K. McGuire, M. Bell, M. Bitter, K. Bol, K. Brau, D. Buchenaver, T. Crowley, S. Davis, F. Dylla, H. Eubank, H. Fishman, R. Fonck, R. Golastor, B. Grek, R. Grimu, R. Hawryluk, H. Hsuan, R. Hulse, P. Izz', R. Kaita, S. Kaye, H. KugeI, D. Johnson, J. Manickam, D. Manos, D. MansEielä, E. M-zzucato, R. McCann, D. Mccune, D. Monticeljo, R. Motley, D. Mueller, K. lasa, ' M. Okabayashi, K. Owens, W. Park, M. Reusch, w. Sauthoff, G. Schmidt, S. Sesnic, ${ }^{+}+$J. Strachan, C. Surko, "* R. Slusher, * H. Takahashi, F. Tenney, P. Thomas, $\$$ J. Valley, ${ }^{*}$ R. White Plasma Physics Laboratory, Princeton University
Princeton, New Jersey 08544

* This work supported by the United States Department of Energy Contract No. $\mathrm{DE}-\mathrm{ACO} 2-\mathrm{CHO}-3073$.

** Bell Laboratories, Murray Hill, New Jersey

$+$ Japan Atomic Energy Research Institute, Toka1, Japan

t+ Ingtitut für Plasma Physik, Garching, F.R. Germany

$\$$ JET-Joint Undertaking, Abingdon, United Kingdom

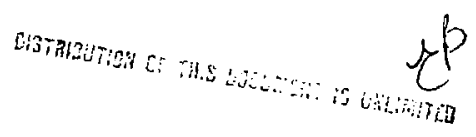


Abstract

A new pressure driven instabilfty has been observed in PDX neutral. beam neated aischarges. It occurs for $\left\langle\beta_{T}\right\rangle q>0.045$ and is associated with a significant loss of fast ions and a drop in neutron emission. As much as 20408 of the beam heating power may be 1ost. The instability occurs in repetitive oscillatory bursts of $<1$ msec duration at $1-6$ msec intervals. It has been dubbed the "fishbone" instability from its characteristic signacure on the Mirrov coils. Fxom the soft $x$-ray detector array, it is identified as an $m=1$ mode; the Mirnov coil signals are synchronous with it but indicate $m>2$. The oscillation frequency within a fishbone burst is $\sim 10$ $\mathrm{kHz}$, but precurso:s at $50-150 \mathrm{kHz}$ are sometimes observed. Much higher Erequency oscillations, up to $\sim 500 \mathrm{MHz}$, have been observed as well.

1. Basic Observations of MHD Activity

Under normal conditions in FDX $\left(I_{p}>300 \mathrm{kA}, B_{T}>1.2{ }^{\prime}\right)$, very little MHD activity is detected by a Mirnov coil. When detectable magnetic perturbations do occur, the mode is usually an $m=2, n=1$ which rotates in the electron diamagnetic direction. The main type of MHD activity observed on the soft $x$-ray array is an $m=0, n=0$ sawtooth oscillation with an $m=1$, $\mathrm{n}=1$ precursor mode. The sawtooth period in an ohmic plasma can vary from 5 to $10 \mathrm{msec}$; with neutral beam injection, the period can extend to $50 \mathrm{msec}$.

The radil of the $q=1$ surface for a $q_{s h}(a) \sim 3^{\star}$ discharge are $\approx 8$ and $\approx 16 \mathrm{~cm}$ for ohmic and neutral beam heated discharges respectively. The sawtooth oscillaticns observed in the ohmic plasma are not correlated with the

\footnotetext{
We define $q_{s h}(a)=q_{C y i}(a)\left\{1+\left(a / R_{0}\right)^{2}\left(1+\left(\beta_{p}+\ell_{i} / 2\right)^{2} / 2\right)\right\}$, the lowest order correction to the cylindrical aperture safety factor.
} 
signals from the Mirnov cofls. Table 1 contains information on typical MHD activity for both ohmic neutral beam heated discharges. Eor low power neutral beam injection ( $1-2$ beams), the $m=1$ mode observed on the soft $x$-ray signal in the plasma core couples to the Mirnov coils. This coupling is strongest at the fall of the sawtooth osclllation. The oscillation on the Mirnov coil is in phase with $m=1$ mode in the plasma core. The frequency of the oscillations is about 5-10 times greater than in an ohmic plasma and the mode iotates In the ion diamagnetic direction [1].

When continuous $m=2$ activity is present in ohmic or neutral beam heated low-q alscharges, the global confinement time is about half that of a sawtooth type. When the $m=2$ activity grows in amplitude a clear decrease in the $B_{p}-l_{1} / 2$ signal is observed. The $m=2, n=1$ activity also modulates the neutron emission and the charge-exchange flux. The fast ion slowing-down spectrum is moculated in amplitude but does not change in shape with the $m=2$ activity present. Discharges which have continuous $m=2, n=1$ mode activity present, are not used in our scaling studies and are not further discussed in this paper.

\section{FIshbone MHD Activity}

The ncrmal structure of the sawtooth oscillations changes with injection of $3-4$ beams at low toroldal field. Instead of a single growing envelope of $m=1$ before the fall of the sawtooth, many bursts of $n=1$ localized near the $q=1$ surface appear in the soft $x$-ray slgnal during the rise of the $m=0$, $\mathrm{n}=0$ part. These bursts of $\mathrm{n}=1$ oscillations are very cleariy observed on the Mirnov colls (Fig. 1). Using Fourier decomposition of the signals, these oscillations are found to be rotating in the lon diamagnetic drift direction (in the beam injection direction). The mode nimber is afficult to identify, 
but it appears that the oscillations are due to a spectrum of modes with $m>2$ $[2,3]$

The MHD activity near the $q=1$ surface is also observed on various diagnostics. The $2 \mathrm{~mm}$ microwave interferometer through the central chord shows $\delta \bar{n}_{e} / \bar{n}_{e}=48$, which is consistent with the observation of $\delta n_{e} / n_{e}=5-108$ observed by $\mathrm{CO}_{2}$ laser and microwave scattering. The radial wavelength estimated from $\mathrm{CO}_{2}$ scattering is $>5 \mathrm{~cm}$. The $\mathrm{Ti} x \mathrm{xI}$ radiation from the plasma core shows the same behaviour as the central $x$-ray channels.

At the plasma edge, the fishbone activity is completely different. The signal observed with the ultra-soft $x$-ray detectors exhibits an inverted sawtooth-type oscillation when the fishbone activity is present. Similar time behavior is detected on CIII radiation and $L_{\alpha}$ hydrogen radiation.

At the onset of a single fishbone, a higher frequency $50-150 \mathrm{kHz}$ precursor oscillation was observed. From the Mirnov coils and the soft $x$-ray system a clear identification of the mode number cannot be made. However, the mode appears to come from a region around the $q=1$ surface. This high frequency fluctuation has $a \widetilde{B}_{\theta} / B_{\theta}$ amplitude which is about 10 times large: in a $250 \mathrm{kA}$ than in a $400 \mathrm{kA}$ discharge.

When the fishbone activity is very strong, typically at low toroldal fleld and high beam power, the central soft $x-r a y$ signal shows a decrease like a low amplitude sawtooth osclilation. The inversion radius is determined to be $r=20 \mathrm{~cm}$ and the inverse sawtooth pattern extends to the plasma boundary. The long period, large amplitude sawtooth oscillations observed at lower beam power begln to disappear. Under these conditions the parallel ton distribution function at $E=5-10 \mathrm{kev}$ measured by active charge-exchange, also shows strong sawtooth-like oscillation corralated with fishbones. These also extend out to the plasma boundary wit. an inversion point similar t- that seen 
in the $x$-ray signal. This evident fleld ergodicity or reconnection at each fishbone must to some degree enhance thermal energy transport.

\section{Scaling of the Fishbone Activity}

A simple empirical scaling of the fishbone perlod, $\tau_{f b}$, with toroidal field is observed, $\tau_{f b} \propto B_{T}$ foi constant current $(I p \sim 300 \mathrm{kA}$ ), R/a $=143 / 42$ $\mathrm{cm}, \mathrm{B}_{\mathrm{T}}$ between 0.7 and $1.7 \mathrm{~T}$, and four $\mathrm{D}^{\circ}$ beams injecting Into an $\mathrm{H}^{+}$plasma (Fig. 2a). The variation of $\tau_{f b}$ with beam power and plasma current is weak. At a toroidal field of $2 \mathrm{~T}$, the flshbone activity is very weak, even with four beams, and the soft x-ray signal is more like the classic sawtooth oscillation. The growth rate of the fast $m=1$ mode oscillation during the fishbone is about 7 times faster at $0.7 \mathrm{~T}$ than at 1.7T (Fig. 2b). Thus for high beam power, and low toroidal field (and thus $h \perp g h\left\langle\beta_{\mathrm{T}}\right\rangle \mathrm{q}$ ) the period between fishbones is short and the growth rate is fast.

The scalling of the frequency of the $m=1$ mode during the fishbone has been studied as a function of the beam injection energy $\left(E_{i n j}\right)$, the abscrbed beam power ( $P_{\text {abs }}$ ), the plasma current, and the toroidal field strength. A linear dependence on $E_{i n j}$ (Fig. $3 a$ ) and an inverse dependence on $I_{p}$ (Fig. $3 b$ ) are found, with little or no dependences on $P_{a b s}$ or $B_{T}$. The toroidal rotation frequency of the $m=1$ mode scales approximately as $v_{\phi}=94 E_{\text {inj }}(\mathrm{keV}) / I_{p}(k A)$ $\mathrm{kHz}$. where $\mathrm{v}_{\phi}=2 \pi \mathrm{R}_{\mathrm{O}} \mathrm{V}_{\phi}(\mathrm{Hz}) \mathrm{cm} / \mathrm{sec}$ for an $n=1$ mode.

This mode rotation velocity is in general significantly greater than the near-central plasma toroidal rotation velocity as measured from the Doppler shift of TixVII forbiaden-line radiation. In addition, the inverse current dependence of the mode rotation speed disagrees with the measured plasma rotation scaling. On the other hand, the observed mode rotation frequency is very similar to the precession frequency of deeply trapped energetic particles 
at about $0.6 \times$ the beam injection energy. The precession frequency for fast ions can be estimated by:

$$
\begin{aligned}
v_{\phi} & =v_{b}^{2} /\left(4 \pi R_{o}{ }^{2} \Omega_{c i}\right) \cdot\left(B_{T} / B_{\theta}\right) \\
& =162 E_{i n j}(k e v) / I_{p}(k A) \mathrm{KHz} .
\end{aligned}
$$

This result suggests that a resonance may exist between the MHD mode and the beam lons which could account for the loss of beam particles. It is also possible that such a resonance could contribute to the instability.

\section{East Ion Effects and Fishbone Model}

Large bursts of charge-exchange neutral efflux are observed which are clearly correlated with the fishbone actlvity. These are strongly peaked in the pexpendicular direction and modulated at the $5-20 \mathrm{kHz}$ of the $\mathrm{m}=1$ mode. At low fishbone amplitudes, the energy range of these neutrals is $E_{i n j} / 2$ to $E_{i n j}(50 \mathrm{kev})$, while at high amplitudes, it extends from thermal energies up to $1.5 \mathrm{E}_{\mathrm{inj}}$. At low particle energies, the background specles neutrals are seen to contribute to the spikes. The presence of particles at energies as high as 75-80 kev indicates that a strong accelerating mechanlsm is present in the plasma. An electrostatic probe in the shadow of the limiter was used to detect frequencles up to $1 \mathrm{GHz}$. The result shows a broad band of RF noise up to $500 \mathrm{MHz}$, which appears only during the fishbone bursts. Thus lower hybrid waves, ion cyclotron waves, or the MHD activity itself could be responsible for the acceleration of the beam particles. 
The slowing-down spectra of the beam particles show significant depletion in the range from $E_{i n j} / 2$ to $E_{i n j}$ (see Fig.4). At eriergies above $\sim 35 \mathrm{keV}$, the spectrum is clearly depleted from its original level after each fishbone and begins to recover between events. At energies below $E_{i n j} / 2$, however, while strong spikes are observed at high fishbone levels, we have not been able to identify a region of the angular spectrun which is depleted just after the fishbone. In the angular scan range available, from counter-nearperpendicular to counter-parallel, the charge-exchange spikes and the depletion are seen to occur primarily at the rear-perpendicular angles.

Rapid decreases in the neutron emission are observed at each burst of MHD activity (Fig.1). The neutron signal can decrease by as much as 408 during a Eishbone burst. Observations of fast neutron decays have been described as "Fast ion discuptions" on PLT, which has tangential "atral beam injection [4].

In order to estimate the loss in heating power which accompanies the observed loss of fast ions, a numerical "fishbone model" was used in the Monte Carlo beam orbit section of the kinetic code [5]. A perpendicular loss cone for particles with $E>35 \mathrm{keV}$ and $\left|v_{\|} N\right|<0.125$ in the horizontal midplane was switched on for $0.4 \mathrm{msec}$ every $3 \mathrm{msec}$ to reproduce the envelope and period of the fishbone structure for a typical $1.0 \mathrm{~T}$ discha: : The model gives a reasonable match with the observed rapid depletion of near-perpendichlar fast ions after each fishbone, the overall slowing-down spectrum and the neutron modulation. The model was used to analyze the $1.0 \mathrm{~T}$ power scan which showed moderate $\left\langle\beta_{T}^{d i a}\right\rangle$ saturation versus power and moderate Eishbone activity [2]. Figure $5 a$ shows a comparison of the axperimental betas and those calculated in the kinetic code both with and without the fisnbone model losses. Figure 5b shows the corresponding change in the thermal confinement and the net heating 
power to the electrons and ions. In this case the conclusion is that the observed saturation of heating could indeed be due to loss of fast ions.

\section{Stability Calculations}

A theoretical study of MHD activity in PDX high beta discharges has been made using a full non-linear, 3-D resistive code, H.I.B., which utilises a large aspect ratio expansion [6]. For the large sawtooth type activity with $\left\langle\beta_{T}\right\rangle q<.025$ (see Table 1), good agreement is found between the calculated and the observed soft $x-r a y$ and Mirnov coil signals. The non-linearity of the modes and the proper treatment of the vacuum region were found to be essential for these good comparisons. The results indicate that the modes observed at these large amplitude sawteeth are due to a non-linear free boundary resistive mode with a strong $m=1$ kink component.

The critical $\left\langle\beta_{T}\right\rangle$ for ideal internal modes calculated by the pest code [7] tends to decrease monotonically as the edge $q$ increases [2] . The critical beta for ballooning modes (infinite $n$ ) is close to the experimentally achievable maximum beta. Furthermore, the critical beta of the ideal internal $\mathbf{n}=1$ mode is close to the onset of the fishbone activity. The potential significance of the internal $n=1$ mode was discussed theoreticaliy in [8] and some experimental indications were presented by the JFT-2 group [9].

\section{Co- and Counter-Injection Comparison}

A short counter injection experiment was run to study the effect of the fast ion precession being in the opposite direction to the plasma rotacion. The results were very encouraging: no fishbone activity was observed and $\left\langle\beta_{T}\right\rangle$ of 2.78 was obtained at $B_{T}=0.9 T$ and $q_{g h}=2.0$. The sawtooth activity in the co- and counter-injection cases was very different. In the counter- 
TABLE I

MHD ACTIVITY IN PDX WITH NEUTRAL BEAM INJECTION

\begin{tabular}{|c|c|c|c|c|c|}
\hline & \multicolumn{3}{|c|}{ Normal Discharge } & \multicolumn{2}{|c|}{$m=2$ DISCKARGES } \\
\hline & 애 & $1-2$ BEAMS & 3-4 BEAMS & 애 & HITH NEUT RAL BEAMS \\
\hline $\begin{array}{l}\text { ACTIVITY OBSERYED } \\
\text { ON SOFT X-RAY } \\
\text { SIGNAL }\end{array}$ & & & & nonamuarsm & \\
\hline$\langle\beta\rangle, q_{\Psi}$ RANGE & $\sim .01$ & $\leadsto, 025$ & .045 & $\sim .01$ & -.025 \\
\hline $\begin{array}{l}\text { X-RAYS } \\
\text { MIRNOV COIL }\end{array}$ & $\begin{array}{l}\text { SAWTEETH AND } m=1 \\
\text { VERY LOW LEVEL OF } \\
\text { MHD ACT IYITY }\end{array}$ & $\begin{array}{l}\text { LARGE SAWTEETH } \\
\text { COUPLING TO MI GNOV } \\
\text { COIL AT FALL OF } \\
\text { SAWTOOTH } m \geq 2\end{array}$ & $\begin{array}{l}\text { FISHBONE ACTIVITY } \\
\text { STRONG COUPLING } \\
\text { OF } m=1 \text { TO MIRNOV } \\
\text { COIL, } m \geq 2\end{array}$ & $\begin{array}{l}m=2 \text { MODE } \\
m=2\end{array}$ & $\begin{array}{l}\text { SAWTEETH THEN } m=2 \\
\text { LARGE } m=2\end{array}$ \\
\hline NEUTRON EMISSION & & $\begin{array}{l}\text { DECREASE (FAST ION } \\
\text { DISRUPT ION) }\end{array}$ & DECREASE $\approx 407$ & & $\begin{array}{l}m=2 \text { OSCILLATIONS } \\
\text { OBSERVED ON } \\
\text { NEUTRON EMISSIVITY }\end{array}$ \\
\hline $\begin{array}{l}\text { ChaRge EXChANGE } \\
\text { FLUX }\end{array}$ & & $\begin{array}{l}\text { SAHTEETH OBSERVED } \\
\text { ON CHARGE EXCHANGE } \\
\text { AND SPIKE AT DROP } \\
\text { OF SAWTOOTH }\end{array}$ & $\begin{array}{l}\text { LARGE EURST OF } \\
\text { CHARGE EXCHANGE } \\
\text { DURING FISHBONE } \\
\text { AND DEPLETION IN } \\
\text { SLOWING DOWN } \\
\text { SPECTRUM }\end{array}$ & & $\begin{array}{l}m=2 \text { ACTIVITY ON } \\
\text { CHARGE EXCHANGE } \\
\text { FLUX. } \\
\text { NO DEPLETION OF } \\
\text { THE FAST-ION SLOW- } \\
\text { ING DOWN SPECTRA }\end{array}$ \\
\hline CONCLUSIONS & $\begin{array}{l}\text { No TRANSPORT } \\
\text { CFFECTS. }\end{array}$ & $\begin{array}{l}\text { No CLEAR GLOBAL } \\
\text { TRANSPORT } \\
\text { EFFECTS OBSERVED }\end{array}$ & $\begin{array}{l}\text { A LOSS OF FAST } \\
\text { IONS FROM THE } \\
\text { PLASHA. A DROP } \\
\text { IN THE CALCULATED } \\
T_{\text {E. }}\end{array}$ & $\begin{array}{l}\text { DECREASE IN CON- } \\
\text { FINEMENT TIHE } \\
\text { IS OESFRVED WHEN } \\
m=2 \text { ACT IVITY IS } \\
\text { PRESENT }\end{array}$ & $\begin{array}{l}\text { CONFIMEMENT TIME } \\
\text { IS } \frac{1}{2}-\frac{2}{3} \text { THE } \\
\text { CONFINEMEHT WITH } \\
\text { SAWTEETH OR } \\
\text { F'SHBONES }\end{array}$ \\
\hline
\end{tabular}


injection case the fall of the sawtooth extended over 2 msec, while with coinjection it occurred typically over a period of $100 \mu \mathrm{sec}$ at high beam power. Transport analysis of discharges with four beam counter-injection, which takes into account classical bad-orbit losses, gives an energy confinement time for the thermal plasma of $35 \mathrm{msec}$, as compared to 15 - 20 msec for similar co-injected plasmas, even in the absence of fishbones at the two beam level (Fig. 5). Furthermore, the central radiation level is much higher than with co-injection, comparable to the local input power to the electrons. Accumulation of hilh $\mathrm{z}$ impurities is seen in the center of the discharge. Laser ablation experiments showed long central impurity confinement times.

The absence of fishbone oscillations in the counter-injection cases may indeed ve due to the opposite directions of plasma rotation and beam ion precession. On the other hand, the $\mathrm{T}_{\mathrm{e}}(x)$ profiles with counter-injection were very similar to those observed with cc-injection, but there are infications that $z_{e f f}(r)$ was peaked on axis. This suggests that the $q(r)$ profile shape and, specifically, a higher $q(0)$ may play an important role ifi the enhanced stability of the counter-injection cases.

The relatively high thermal confinement of the counier-injected plasmas, and the observed impurity accunulation, may be related to the negative potential developed in the plas.la with counter-injection [10]. Monte-Carlo beam thermalization calculations taking into account a \pm 6 kV central potential (corresponding to $v_{\phi}(0)=c E_{r} / B_{\theta} \Rightarrow \pm 2 \times 10^{7} \mathrm{~cm} / \mathrm{sec}$ ) have been made. The effesta of a positive potential (co-rotation) on co-injection heating are found to be negligible, while the presence of a negative potential (counter-rotation) is calculated to improve counter-injection heating effic ency by only $\sim 158$. The rotation speeds taken in these calculations are higher than the experimental conditions. 


\title{
7. Conclusions
}

\begin{abstract}
The observation of a $\left\langle B_{T}>q^{1.15}\right.$ limit in PDX [2] can be explained by a loss of fast ions due to the fishbone activity, although an adritional deterioration of thermal confinement cannot be ruled out. By modeling the charge-exchange measurements of the fast ions and the neutron emissivity, code results indicate that $20-408$ of the heam heating can be lost due to fishbone activity. From the soft $x$-ray system this high beta activity is identified as an $m=1$ mode, rotating in the ion diamagnetic direction. Stability calculations with PEST suggest that pressure-driven (possibly non-ideal) internal modes may be responsible for the fishbone activity. With perpendicular counter-injection in PDX high beta values with good energy confinement (although subs antial beam orbit losses) were obtained without Eishbone activity present. The mechanism of interaction of the beam ions and MHD activity, as well as the role of the $q$ profile in the fishbone instability, are the subject of continuing investigation.
\end{abstract}

\section{Acknowledgments}

We wish to express our appreciation for the efforts by M. Williams, T. Kozub, and the neutral beam technical group in operating and maintaising the PDX beam system, to the technicians and engineers who keep PDX operating, and for the continuing support by Dxs. H.P. Fur' ᄀ, P. H. Ratherfora, and especially, D.M. Meade. 
References

[1] Bel1, M., et al., to be published in Controlled Fusion and Plasma Physics, Proc. of the 10th European conference(Moscow 1981) vol 2; Davis, S,L., et al., Auxiliary Heating Results from PDX and PLT, 9th Annual Conference on Plasma Physics 1982 Oxford.

[2] Johnson, D., et al., in Proc. of the Ninth International Conference on Plasma Physics and Controlled Nuclear Fusion Research, Baltimore, 1982 (to be published).

[3] Dunlap, J.L., et al., Phys. Rev. Lett. 46 (1982) 538 .

[4] Strachan, J., Princeton Plasma Physics Laboratory Annual Report \# PPPL-Q- 38 .

[5] Hawryluk, R.J., Proc, of the Course on Physics of Plasmas close to Thermonuclear Conditions, Report EUR FU BRU/XII/476/80,Vol. 1,p.19 (1980): Goldsscr, R.J., et al., J. Compt. Phvs. 43 (1981) 61.

[6] Park, W., Monticelle, D., White, R., et il. Proc. U.S.-Japan Theory workshop on 3-D MHD Studies For Toroidal Devices,Oak Ridge TN. (1981).

[7] Chance, $M$. , et al., in Proc. of the 7th International Conference on Plasma Physics and Controlled Nuclear Fusion Research, Innsbruck Vol.1 (1978) p.677: Grimm R.C., in Methods in Computational Physics, vol. 16 (Killeer., J., Ed.) Academic Press, New York (1976) 253.

[8] Tokuda, S., et al., Nucl. Fusion 22 (1982) 661; Bussac, M.N., et al., Nucl. Fusion 21 (1981) 1409.

[9] Yamamoto, s., et al., Nucl. Fusion 21 (1981) 993.

[10] Oren, L., et al., Bull .Am. Phys. Soc. 26 (1981) B58. 


\section{Figure Captions}

Fig. 1 Shows the time evolution of the soft $x$-ray emission from a central channel, the $\dot{B}_{B}$ signal from a coil near the outer wall of the vacuum vessel and analog output from a fast neutron detector. Expansion of the data from 479 to ios - sec is also shown.

Fig. 2 (a) Variation of the fishbone oscillation period with toroidal field strength for circular plasmas. (b) Dependence of the growth rate $r$ of the fishbone oscillation on toroidal fleld, where $1 / \gamma$ is defined here as the time between the half and full amplitude of the burst.

Fig. 3 (a) Dependence of the toroidal rotation frequency of the fishbone $m$ $=1$ mode on the plasma current, $I_{p}$ (b) variation of the toroidal rotation frequency (in $\mathrm{kHz}$ ) with. injection energy ( $E_{\text {inj }}$ ) of the neutral beams for $I p=250-290 \mathrm{kA}$ and $\mathrm{R} / \mathrm{a}=143 / 42 \mathrm{~cm}$. The numbers close to the data points in iicate the beam power injected in MW.

Fig. 4 Charge-exchange spectra in the courter-near-perpendicular direction of the slowing down beam ions for a two-beam no fishbone discharge, overlaid with a four beam stvere flshbone discharge. The depletion of beam uns from just below $E_{i n j}$ down to $E_{i n j} / 2$ is very evident. Note that these spectra were obtained by sweeping the energy analyzer in time, so fishbone spikes appear to be localized in energy, while in fact they are not, but rather they are localized in time. 
Fig. 5 (a) Shows a comparison of the experimental beta's and those calculated in the kinetic code with and without the fishbone model losses. (b) Shows the corresponding change in the thermal confinement and the net heating power to the $e^{\prime}$ strons and ions. 


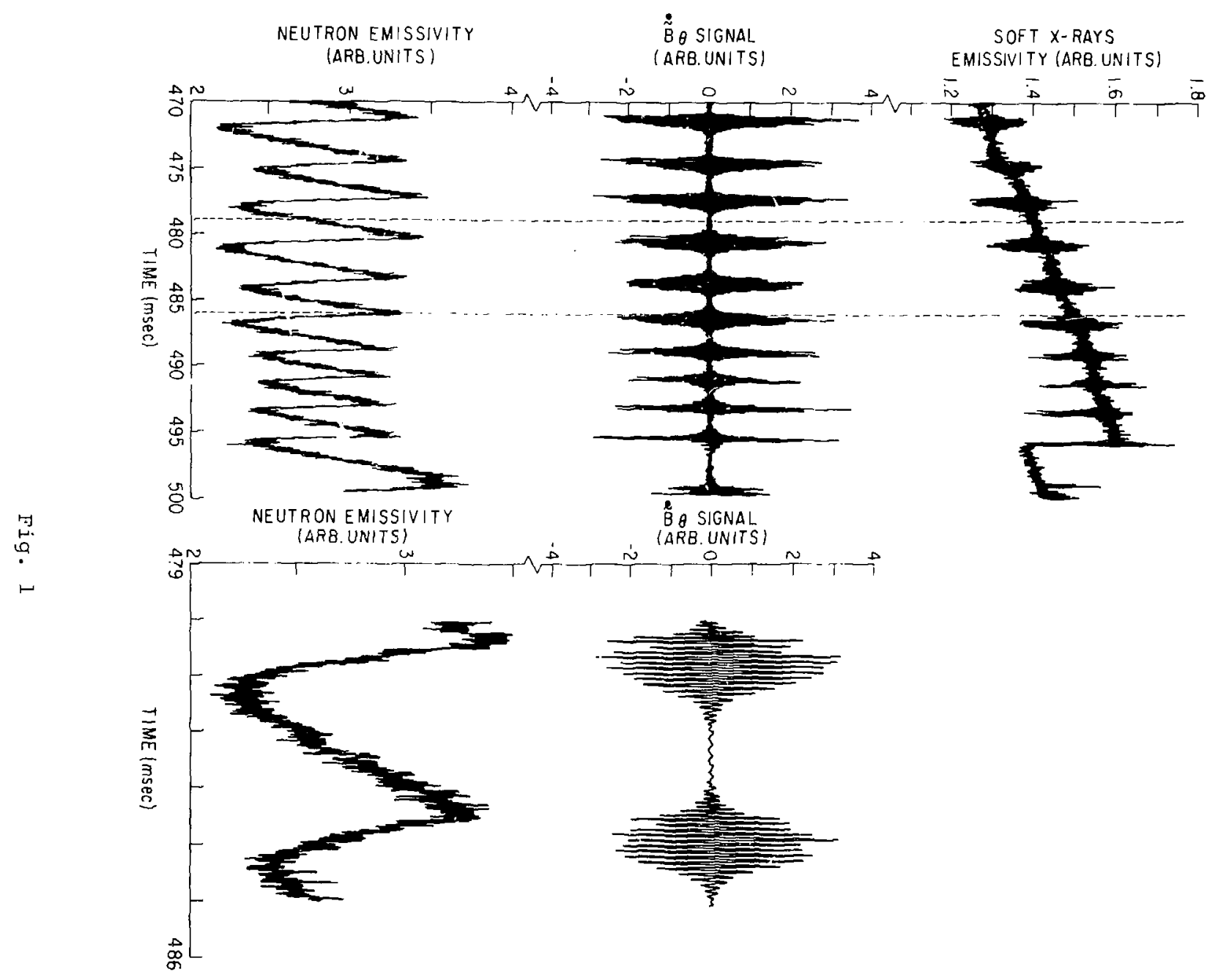




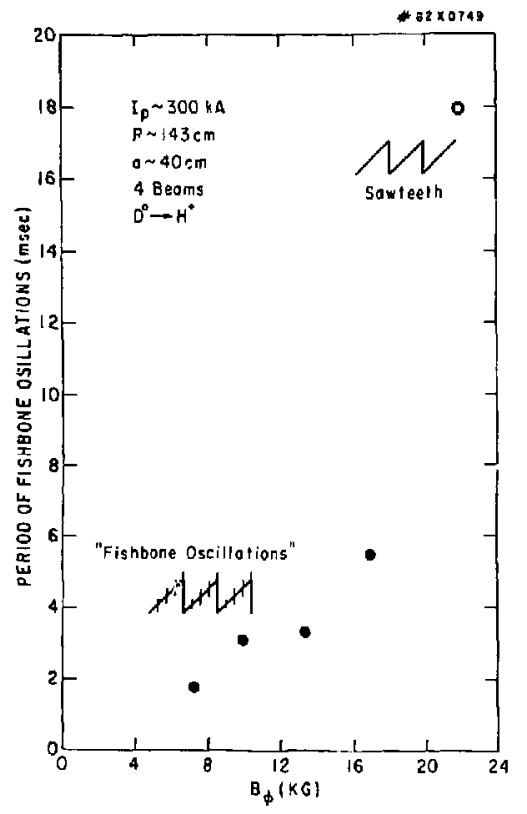

(a)

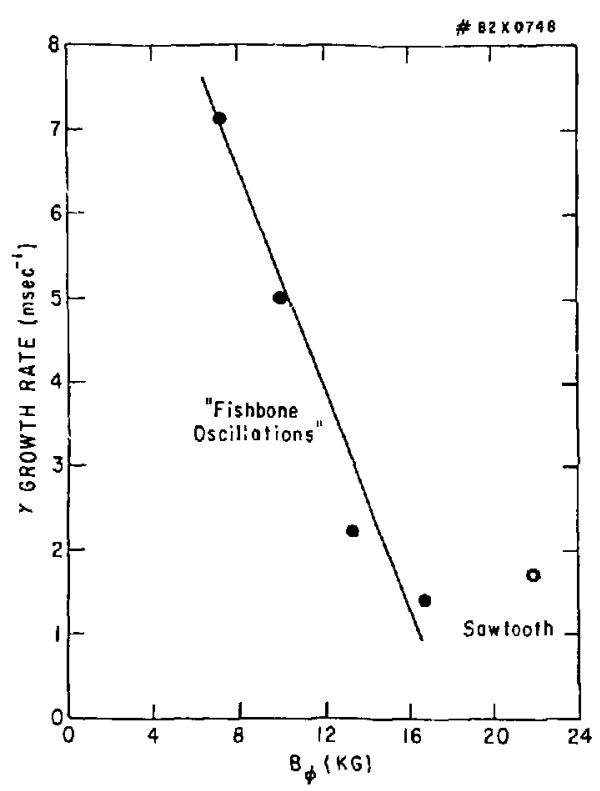

(b)

Fig. 2 

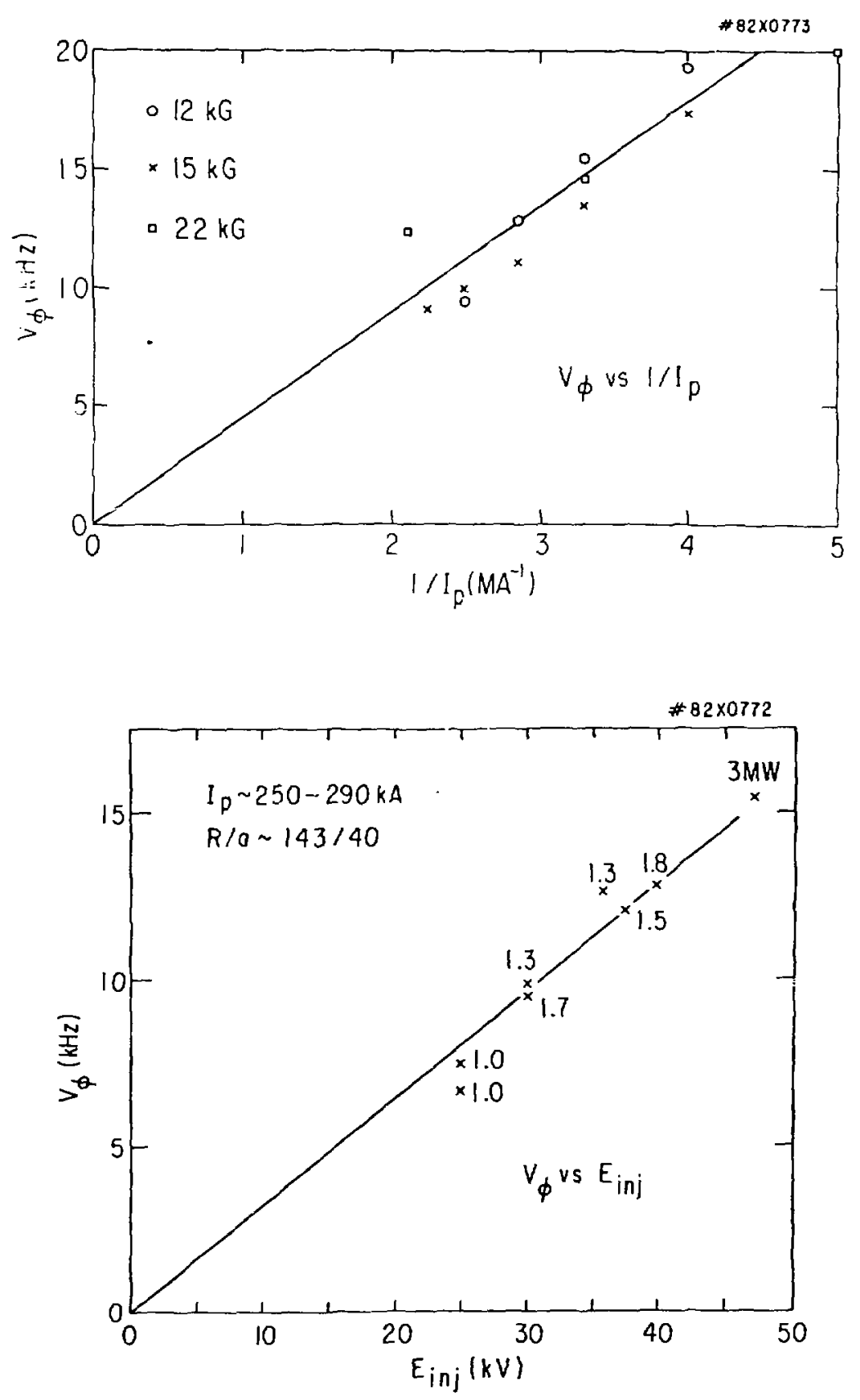

Fig. 3 


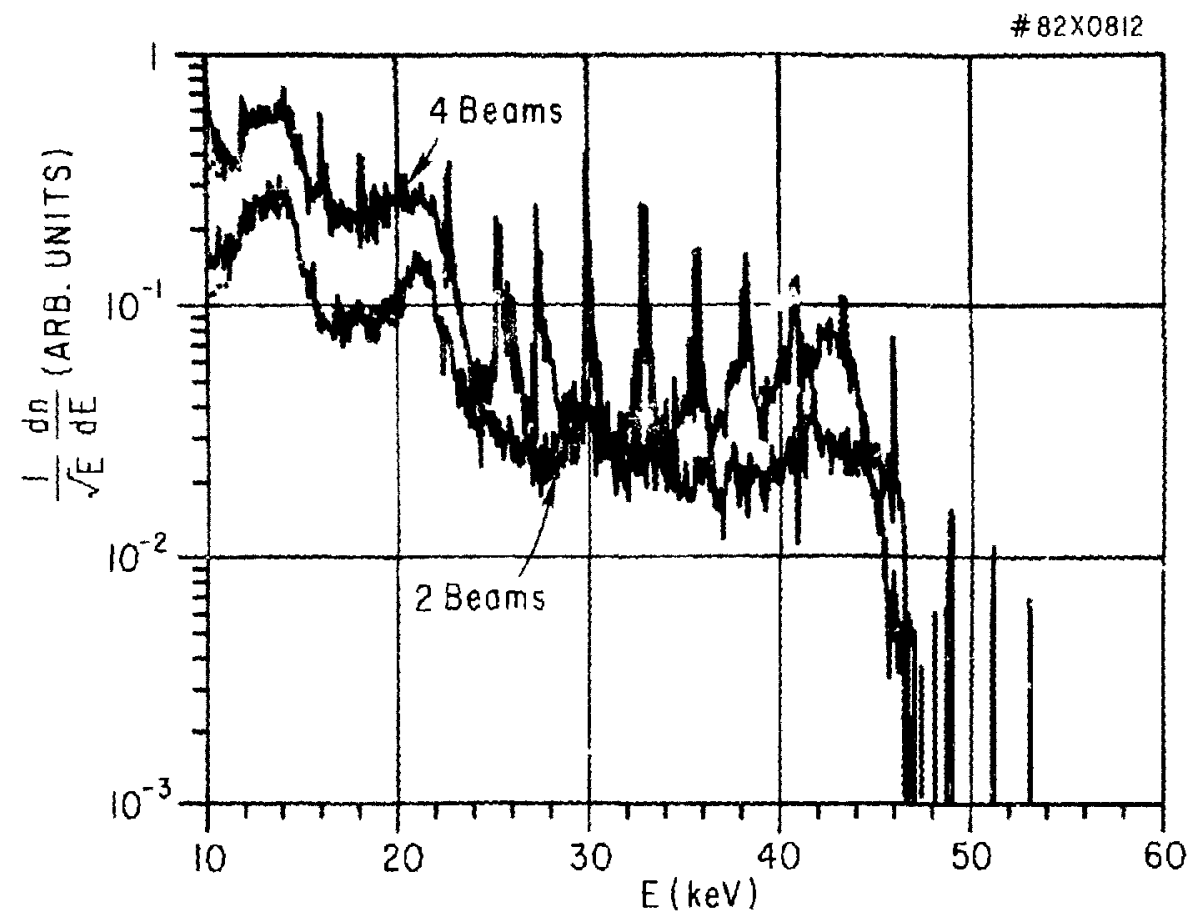

Time $(7.5 \mathrm{msec} / 10 \mathrm{keV}) \rightarrow$ 
\# $82 \times 0807$
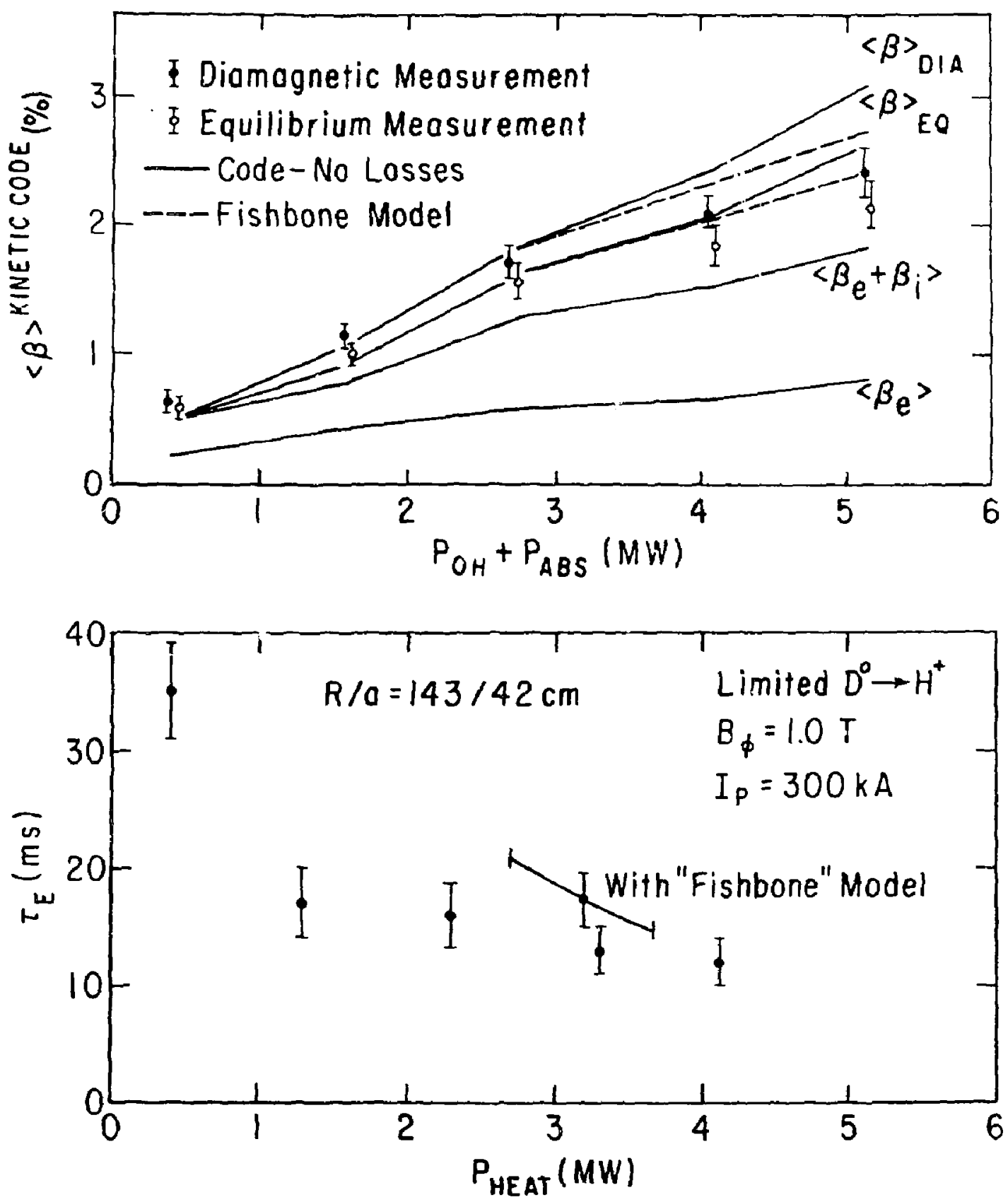

Fig. 5 